\title{
Second Corinthians and Paul's Gospel of Human Mortality
} How Paul's Experience of Death Authorizes His Apostolic Authority in Corinth

[Der zweite Korintherbrief und das Evangelium des Paulus über die menschliche Sterblichkeit. Wie Paulus' Erlebnis des Todes seine apostolische Autorität in Korinth autorisiert.]

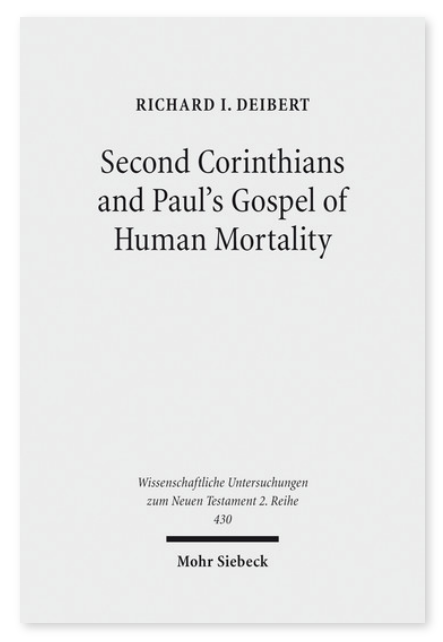

2017. XIII, 280 Seiten. WUNT II 430

ISBN 978-3-16-153378-5

DOI 10.1628/978-3-16-153378-5

eBook PDF $94,00 €$

ISBN 978-3-16-153377-8

fadengeheftete Broschur 94,00€
Veröffentlicht auf Englisch.

In diesem »close reading « des 2. Korintherbriefes und der Untersuchung der im griechisch-römischen Korinth

vorherrschenden Haltungen dem Tod gegenüber schlägt Richard I. Deibert vor, dass Paulus' Sterblichkeit als Schlüssel dient, um sowohl das Rätsel des Einbruchs seiner Autorität in Korinth als auch die Essenz seines Evangeliums zu verstehen. Durch das Erlebnis seines eigenen physischen Todes erlebt Paulus die »Leblosigkeit« des wiederauferstandenen Jesus, welche ihm paradoxerweise Leben überträgt und durch ihn an seine Gemeinde. Paulus erkennt, dass der Tod in eine Quelle des Lebens verwandelt und somit die menschliche Sterblichkeit mit rettenden Kräften ausgestattet wurde. Diese Untersuchung der menschlichen Sterblichkeit macht deutlich, wie wichtig es sowohl zu Paulus' Zeiten als auch heutzutage war und ist, den Menschen als untrennbare Einheit von Körper und Geist zu begreifen und die Theologie auf die menschlicheErfahrung zu gründen. Richard I. Deiberts Arbeit ist nicht nur für Studierende der frühchristlichen und neutestamentlichen Geschichte interessant, sondern auch für Anthropologen, Philosophen und Theologen.

Richard I. Deibert Born 1958; 1980 BA in Religion at Davidson College, Davidson, North Carolina; 1984 MD at University of Florida College of Medicine, Gainesville, Florida; 1985 Internship in Medicine and Pediatrics at Emory University School of Medicine, Atlanta, Georgia; 1989 MDiv at Columbia Theological Seminary, Atlanta, Georgia; 2005 PhD in New Testament, University of Cambridge; ordained minister in the Presbyterian Church (USA), with Eastern Orthodox leanings; served churches in Alabama, North Carolina, and Florida; currently practicing hospice and palliative care medicine for the dying with Tidewell Hospice in southwest Florida.

Jetzt bestellen:

https://mohrsiebeck.com/buch/second-corinthians-and-pauls-gospel-of-human-mortality-9783161533785?no_cache=1 order@mohrsiebeck.com

Telefon: $+49(0) 7071-923-17$

Telefax: +49 (0)7071-51104 